that in an infirmary, capable of accommodating, at one time, as many as 150 in-patients, two ordinary physicians and two surgeons are enough to transact the business ; but he recommends, where the number of beds is so considerable, the appointment of a similar number of assistant medical officers, to supply the places of the ordinary physicians and surgeons, in cases of absence, death, or resignation.*

In a table of provincial infirmaries, drawn up by Dr. Walker, and in some hospital reports now before me, I find that the following hospitals have each two physicians and two surgeons, viz. York, Lancaster, Gloucester, Chichester, Durham, Dumfries, Hereford, and Chester. The following have each three physicians and three surgeons, Hull, Liverpool, Leeds, Norfolk, Sheffield, Worcester, and Reading. Derby, Northampton, Huddersfield, and Stafford have each two physicians and three surgeons. The Glasgow and Lincoln infirmaries have each two physicians and four surgeons. The Bedford infirmary has one physician and two surgeons. You will observe that six medical graduates have signed the memorial and address. 'These gentlemen object particularly to the latter part of the rule, which relates to the qualification of physicians. They take general practice, and say it is extremely hard and very improper, that, on account of their being practitioners, they should be disqualified by the rule from being eligible to be physicians to the infirmary. One gentleman is a licentiate of the College of Physicians of London, and several of them, I understand, are licentiates of the College of Surgeons of Edinburgh. In order to conciliate these gentlemen, and render them all eligible to fill the offices of physicians and surgeons, the governors have altered the aloove rules, and have adopted the following: "'That no person shall be eligible to the office of physician to the infirmary, unless he be a graduate of a British or Irish university, or licentiate of the College of Physicians of London. 'That no person shall be eligible to the office of surgeon to the infirmary, unless he be a member or licentiate of the College of Surgeons of London, Dublin, Edinburgh, or Glasgow." Although all the gentlemen who signed the memorial and address are now made eligible, not one of them, I am informed, will take office.

The subject of hospital attendance is of great importance, and not only deserves the attention of the editors of the Provincial Medical and Surgical Journal, but also the best consideration of the members of the association. I therefore hope you will insert this communication in your journal, and also take an early opportunity of favouring your readers with an editorial article on the subject. It would likewise be interesting and useful to many of your readers to be informed of the number of beds a provincial hospital must contain to be recognised by the examining boards in London, and if any, and what particular rules and regulations are required by these boards.

$$
\text { Yours, \&c., }
$$
Cumbriensis.

Carlisle, September 24, 1841.

$$
\text { - Collection of Papers. By J. Clark, M.D. }
$$

\section{HERNIA REDUCED BY ICE.}

TO THE EDITORS OF THE PROVINCIAL MEDICAL AND SURGICAL JOURNAL.

Gentegmen,-As every contribution tending to diminish the necessity of operations in surgery $I$ deem to be of importance, perhaps the following facts may be regarded of that nature; and although the practice referred to is well known, yet I doubt whether it be so frequently resorted to as may be desirable, before the last and often fatal practice be adopted,-I mean the operation for strangulated hernia.

Cases of hernia, we all know, are not frequent in private practice, and when they do occur, the surgeon soon gets anxious for the fate of his patient, and very desirous to ward off an operation, which, even in the most skilful hands, is a very serious and dangerous affair. It has unhappily fallen to my lot to see the operation performed, and the patient die within four hours after, and die most evidently from the operation itself, and not from the previous state of the intestine. It is therefore with very great pleasure I can state the complete success in two cases of the application of ice to the tumor. In one of the cases, a female had inguinal hernia of the right side; her symptoms were severe, she had vomiting, pain on pressure, and a good deal of general anxiety. 'The usual remedies were adopted, and as the symptoms were urgent, it was resolved to operate; but, at the suggestion of a brother practitioner, I had a bladder of ice kept for some hours over the tumor; the result was a quick relief from pain, and a very slight manipulation sufficed to return the intestine. In the other case, the patient was a strong seafaring man, who had suffered the usual symptoms of strangulated inguinal hernia for twenty-four hours before I saw him; after bleeding, I attempted reduction by the taxis, but was compelled to desist from the pain it produced. Ice was now applied, and in three hours afterwards the man reduced the tumor himself, without any difficulty. 'The immediate effect of this application in such cases is very satisfactory to the patient; the tension of the part is removed, and consequently the pain: then follows the diminution of bulk by the contraction produced, which again seems happily to end in the return of the intestine.

Should the foregoing statement lead surgeons to the more general trial of this remedy before proceeding to operate, I shall feel much satisfaction.

Your obedient servant,

Edward Humpage.

Bristol, Sept. 27, 1841.

\section{GRATUITOUS SERVICES OF MEDICAL MEN.}

TO THE EDITORS OF THE FROVINCIAL MEDICAL AND SURGICAL JOURNAL.

Gentumane, - I send you the Liverpool Standard, which contains a letter from me, signed "Medicus," for the purpose of reprinting it in the Provincial Medical and Surgical Journal, if you think the subject of sufficient interest to your readers. It may, perhaps, appear strange that I should hazard such sentiments as those of remu- 
neration to medical officers in the face of a meeting where an appeal is made for medical aid-but the subject has often engaged my thoughts, and as often I have been compelled to come to the same conclusion; and this, from a conviction that one amongst many other causes of the lowered state of the medical profession, at least in Liverpool, is the immense extent of gratuitous practice; but as it is almost preposterous to expect that such opinions will be acted upon, by merely promulgating them, I have thought the present opportunity favourable to draw attention to them, although I can scarcely expect them to be at once adopted; but the question may be worthy of examination, and thereby awaken attention to the subject.

\section{I am yours faithfully,}

$$
\text { Sept. 21, 1841. Thomas JeFrReYs. }
$$

\section{"THE LIVERPOOL DISPENSARIES.}

\section{"To the Editor of the Liverpool Standard.}

"Sir,-A meeting being appointed for the purpose of relieving the lepressed funds of the dispensaries, patronised, and to be presided over, by the Mayor, upon Friday next, I hope that a few remarks upon the subject may not be considered as quite out of place, from one who has worked hard, studied, and watched the progress and proceedings of the medical institutions of Liverpool for now nearly forty years. No one, I think, can doubt the usefulness and extent of the dispensaries in this town; and with the exception of Manchester, the numbers attended by the medical officers is not equalled by any similar establishment under the direction of one committee, throughout the whole of her Majesty's dominions, in which may be included the metropolis itself. It cannot, therefore, be a matter of much surprise that these institutions should labour under pecuniary embarrassment, as has always been the case once in about every five, seven, or ten years. And why is it so ? for it is evident that there is no want of charitable feeling amongst our mercantile community, and there ought not to be any want either of pecuniary means; although experience has proved beyond the possibility of doubt, that not only the dispensaries, but almost every charitable institution in the town, has been mainly supported by those who can least afford it. Some of those (for I will not say all) who have been most successful in mercantile affairs, are so much absorbed in their extensive concerns that, it is much to be feared, they consider the subject of charity unworthy of their attention. Unfortunately, it happens that although there is no charity in the town which does more extensive and real good, at so small a cost, as the relief which the dispensaries afford to those who are afflicted with poverty and disease, it is painful to acknowledge that their high standing is not in the same proportion appreciated.

"The first consideration of the committees ought to be, and no doubt is, the relief of the poor overwhelmed with distressing poverty and dire disease ; but there is a second consideration, which comes so close upon the well-being of the medical institutions. that I trust I shall not. be considered as inimical to such establishments, nor offensive to my medical brethren, if I venture to point out the advantage it would be to both, if all the medical officers were more or less remunerated for their services, by which, I am confident, the poor would be better attended, and the standing of medical men would be heightened.

"At present 50,000 patients are annually prescribed for at the north and south dispensaries, by which there must be either one of two evils viz., if the medical officer is both zealous and conscientious in the discharge of his duties, the probability is, that he is compelled to neglect his private professional interests, in such a manner as to lay the foundation for irremediable anxiety so long as he lives. If, on the contrary, he neglects his duties, his professional character is injured, and, what is of more consequence to the community, the objects and designs of the institution are not carried out.

"The great anxiety which medical men evince of being appointed to public institutions, leads to a very natural inference, that there are advantages to be derived from them unknown to the public, and which medical men will not disclose; and, no doubt, the opportunity of witnessing a great variety of cases and practice is considerable; but as this must entirely depend upon the use which each individual makes of it, it is no criterion of superiority; for I am one of those who think that twenty cases closely, diligently, and scientifically watched, are more advantageous to the practitioner and the patient than one hundred visited and attended superficially. Now, as this subject will sooner or later become an object of parliamentary investigation and arrangement, I am anxious that Liverpool should be one of the foremost in testing its practicability.

"I would, therefore, urgently suggest that there should be no honorary officers attached to any medical establishment in Liverpool, and that the fees paid to those so called, by pupils, should belong to the funds of the institution, and become a part and parcel of its permanent resources.

"I should also suggest that no physician or surgeon should ever be appointed to any hospital or disperisary unless he will consent to become at least a clinical teacher, if not something more, and that the services of all medical officers should be limited to seven, ten, or fifteen years, agreeable to their own wishes and prospects for private professional confidence; beyond which period he either injures himself, the profession, or the objects of the institution.

"By this modification in the constitution of medical charities, the wants of the sick poor would be provided for, more rigid attendance would be secured, and much anxiety, if rot mortification, would be aroided to the young medical aspirant, and, in addition to which, the more independent and wealthy part of the community would secure for themselves medical practitioners well grounded, both by claims and pretensions, for the confidence of those who may honour them by their preference.

"These remarks are brought forward from the purest motives, both towards my medical brethren in this locality, the medical profession in general, and, at the same time, of preserving permanent advantages, in future, for every class of those who require medical assistance, from the humblest individual to the most exalted in society; and if $I$ should fail in making any impression, I shall not 


\section{regret having made the attempt. - I am, sir, your bedient servant,}

“ Liverpool, Sept. 20, 1841.”

"Medicus."

\section{UNIVERSITY OF LONDON.}

DEGREE OP BACHELOR OF MEDICINE.

Previously to the year 1842 , candidates who have been engaged during two years in their professional studies shall be admitted to the first examination for the Degree of Bachelor of $\mathrm{Me}$ dicine, on producing certificates to the following effect :-

1. Of having been engaged two years in their professional studies.

2. Of having attended a Course of Lectures on each of four of the subjects comprehended in the following list:-Descriptive and Surgical Anatomy; General Anatomy and Physiology; Comparative Anatomy; Pathological Anatomy; Chemistry; Botany; Materia Medica and Pharmacy; General Pathology; General Therapeutics; Forensic Medicine; Hygiene; Midwifery and Diseases peculiar to Women and Infants; Surgery; Medicine.

3. Of having dissected during nine months.

4. Of having attended to practical pharmacy during a sufficient length of time to enable them to acquire a practical knowledge in the preparation of medicines.

Candidates shall be admitted to the second examination at the expiration of two years after the first examination, on producing the certificates required at that examination.

Previously to the year 1842, candidates who have been engaged during four years in their professional studies, shall be admitted to the second examination for the Degree of Bachelor of Medicine, on producing certificates to the following effect :-

1. Of having been engaged during four years in their professional studies.

2. Of having passed the first examination.

3 . Of having attended a course of lectures on each of two of the subjects comprehended in the list given above.

4. Of having dissected during twelve months.

5. Of having attended a Practical Pharmacy during a sufficient length of time to enable the pupil to acquire a practical knowledge in the preparation of medicines.

6. Of having conducted at least six labours.

7. Of having attended the surgical practice of a recognized hospital or hospitals during twelve months.

8. Of having attended the medical practice of a recognized hospital or hospitals during other twelve months.

9. Of having completed the twenty-second year of their age.

10. Of moral character from a teacher in the last school or institution at which they have studied, as far as the teacher's opportunity of knowledge has extended.

Candidates who have not taken a Degree in Arts, or passed the Matriculation Examination in this University, will be required to translate a portion of Celsus De Re Medica.

\section{NECROLOGY.}

THE medical science of this country has lost one of its brightest ornaments, in the death of Dr. Wm. P. Dewees, which took place in Philadelphia, May 18th, 1841. Dr. Dewees commenced practice at Abington in the year 1789, and removed to Philadelphia in 1796, where he remained until 1812. III health at this period compelled him to remove to the country, and he fixed his residence at Phillipsburgh, Pennsylvania, where he remained until 1817 , when he again returned to the city. In 1826 he was appointed adjunct professor, and in $\mathbf{1 8 3 4}$ professor of obstetrics and diseases of women and children in the University of Pennsylvania. Early, in this last year, Dr. Dewees suffered an attack of paralysis, from which period his health became very much impaired. He, however, delivered a full course during the session of 1834-5, but at the commencement of the following session his health was so feeble as to compel him to resign his professorship, and seek a southern climate. After spending a winter in Cuba, and the succeeding summer at the north, he settled at Mobile. About a year since, he returned to Philadelphia, where he closed his long and useful career, at the age of $\mathbf{7 4}$ years and a few days, full of years and full of honour.

Dr. Dewees had an unusually large practice, and possessed extraordinary tact as a practitioner, with a just degree of confidence in himself, resulting from his vast experience, which led to implicit confidence in him on the part of his patients. As an accoucheur, he had indeed a more extensive experience than any other physician in this country, and in this department he had few if any equals, and no superior.

Dr. Dewees's fame was not confined to this country. He was well known abroad by his writings, which have been more generally quoted by European authors on obstetrics than those of any other American physician, and his opinions are noticed with a degree of respect and deference, which evince that his authority ranks among the highest.-American Journal of Medical Science.

\section{MR. LISTON.}

IN commenting, last week, on a paragraph relative to Mr. Liston, which appeared in one of the daily papers, we assumed, perhaps rather hastily, that Mr. Liston had lent himself to a system of puffing, than which nothing, in our estimation, can be more offensive. We have since been positively assured, that Mr. Liston was in no way cognizant of the "puff" alluded to, and therefore express our regret that we should have converted an inference from certain facts, into an accusation against an innocent man.

During the last twelve months, the columns of the political press have teemed with paragraphs obviously intended to place the name of $\mathrm{Mr}$. Liston constantly before the public eye. $\mathrm{Mr}$. Liston does not countenance this illegitimate notoriety; we have his own word for it, and it must be true. We cannot but congratulate him on his good fortune; he is the only professional man in England who thus enjoys the advantage of being puffed-in spite of himself. 